\title{
The Effect of Individual Care of Case Manager on Breast Cancer Patients
}

\author{
Lingling Wang ${ }^{1}$, Yuhua Ma ${ }^{1, *}$, Junnan Lin ${ }^{2}$ \\ ${ }^{1}$ General Surgery Department, The First Affiliated Hospital of Jinan University, Guangzhou, China \\ ${ }^{2}$ Department of Ophthalmology and Stomatology, The First Affiliated Hospital of Jinan University, Guangzhou, China
}

Email address:

2609308413@qq.com (Lingling Wang),924006463@qq.com (Yuhua Ma), 1075184194@qq.com (Junnan Lin)

${ }^{*}$ Corresponding author

\section{To cite this article:}

Lingling Wang, Yuhua Ma, Junnan Lin. The Effect of Individual Care of Case Manager on Breast Cancer Patients. American Journal of Nursing Science. Vol. 9, No. 3, 2020, pp. 124-126. doi: 10.11648/j.ajns.20200903.18

Received: April 1, 2020; Accepted: April 17, 2020; Published: April 28, 2020

\begin{abstract}
Objective: To assess influence of individual care of case manager on breast cancer patients. Methods: 99 participants who were diagnosed as breast cancer were invested to join our study, their diagnose time is from October 2018 to March 2019. We randomly assign the participants to the two different groups, that include control group $(\mathrm{n}=51)$ and the intervention group $(n=48)$. In control group, the participants received traditional care services which were follow the standards required by the hospital. Additionally, the intervention group participants receive individual care. our researchers collected the information, that include anxiety information, depression information, patient satisfaction and patient informed. We collected data using the following questionnaires: Self-Rating Anxiety Scale (SAS), Self-rating depression scale (SDS) and some simple questionnaire. Result: In participants characteristics, most participants are early breast cancer in our research result [22 (45.8\%) $\& 25(49.0 \%)]$. The number of secondary is metaphase of breast cancer group, it is just a few fewer people than early breast cancer group [18 (37.5\%) \& $20(39.2 \%)]$. In research of satisfaction and informed intervention group has higher score than that of control group in satisfaction assessment and informed assessment. In anxiety status and depression status, the intervention group has better performance than that of control group in SAS and SDS $(53.5+10.44$ vs $41.5+8.82 \& 49.75+9.45$ vs $40.25+5.11)$. Conclusion: The individual care of case manager has good improvement in breast cancer patient's mental health. In particular, the intervention group participants who receive individual care of case manager have better performance in satisfaction research, anxiety research and depression research.
\end{abstract}

Keywords: Individual Care, Breast Cancer, Nursing

\section{Introduction}

Breast cancer had estimated new cancer cases and deaths of ranks tops in all types of cancer, it is a major health problem in women [1, 2]. In 2018 years, although more than 200,000 women are diagnosed with invasive cancer annually, breast cancer mortality has decreased because of advances in screening and improved treatment [3]. There had a small population of cells that display stem cell properties in breast cancer patients' body, the cell function includes clonal long-term repopulation capacity and self-renewal [4]. In addition, an effective therapy is strategies aimed at targeting the breast cancer stem cells. Breast cancer is surrounded with lots of fat pad, which providing the basic niche for tumor initiation and progression $[5,6]$. As the proportion of women diagnosed with early stage breast cancer increases, so too does the population of breast cancer survivors, emphasizing the importance of follow-up care for these women. The nurses detect an early recurrence, it will allow for earlier treatment and can improve overall survival, that is the premise for intense monitoring in breast cancer survivors [7].

In America, only $1 \%$ of the population represents nearly $22 \%$ of total health care expenditure annually. There is disproportionate segment of the nation's health care spending is used to provide care to a tiny subset of the population $[8,9]$. In addition, the individual care can effectively reduce health care costs. Base on the report, super-utilizer-associated health care costs decrease by $26.6 \%$ to $40.9 \%$ when patients seek care for non-emergent con-ditions at appropriate medical facilities 
versus the emergency department $[10,11]$. Furthermore, patients use individual care service in the hospital, that the cost associated with super-utilizer hospital readmission decreases between $12.3 \%$ to $47.7 \%$ [12]. Aim of this study is assess the effect of individual care of case manager on breast cancer patients.

\section{Methods}

\subsection{Participants Enrollment and Survey Methods}

We invest 99 participants to join our study who were diagnosed as breast cancer, their diagnose time is from October 2018 to March 2019. We randomly assign the participants to the two different groups, that include control group $(n=51)$ and the intervention group $(n=48)$. The participants of two different groups receive different nursing services. In control group, the participants received traditional care services which were follow the standards required by the hospital. On the other hand, the intervention group participants receive individual care, the individual care is that according to the patient's needs and preferences to develop the nursing measures for the patient. In addition, our researchers collected the information, that include anxiety information, depression information, patient satisfaction and patient informed. We collected data using the following questionnaires: Self-Rating Anxiety Scale (SAS), Self-rating depression scale (SDS) and some simple questionnaire [13, 14].

Their inclusion criteria were: (1) the patients were diagnosed as breast cancer; (2) Patients volunteered to participate in follow-up; (3) Patients are treated and hospitalized in our medical organization. Their withdraw criteria were: (1) patients had complications in treatment process; (2) The patient also had other severe disease.

\subsection{Statistical Analysis}

Our data analyzer performed the statistical analysis by SPSS 22.0. The $\mathrm{P}$ value, t-test and chi-square test were associated with collection result were analyzed. Besides, the mean standard deviation for statistical description.

\section{Result}

The information of participants characteristics from hospital database, it shows the basic status of participants. Base on Table 1, most participants are early breast cancer in our research result [22 (45.8\%) \& $25(49.0 \%)]$. The number of secondary is metaphase of breast cancer group, it is just a few fewer people than early breast cancer group [18 (37.5\%) \& 20 $(39.2 \%)]$. As the data of two group is not statistical significance, the data of two group is similar.

Table 1. Participants Characteristics.

\begin{tabular}{|c|c|c|c|c|}
\hline Projects & Age (year) & Early breast cancer, $n(\%)$ & $\begin{array}{l}\text { Metaphase of breast } \\
\text { cancer, } n(\%)\end{array}$ & $\begin{array}{l}\text { Advanced breast } \\
\text { cancer, } \mathbf{n}(\%)\end{array}$ \\
\hline Intervention Group, $(\mathrm{n}=48)$ & $53.7 \pm 23.5$ & $22(45.8 \%)$ & $18(37.5 \%)$ & $8(16.7 \%)$ \\
\hline Control Group, $(\mathrm{n}=51)$ & $53.4 \pm 24.7$ & $25(49.0 \%)$ & $20(39.2 \%)$ & $6(11.8 \%)$ \\
\hline P Value & 0.936 & 0.143 & 0.081 & 0.419 \\
\hline
\end{tabular}

The information of satisfaction and informed from the two-simple questionnaire, its score range is from 1 to 10 , scores increase with satisfaction. Participants rated satisfaction based on their impressions. In Table 2, intervention group has higher score than that of control group in satisfaction assessment and informed assessment. In addition, these two sets of data are statistical significance, the two different group have different in satisfaction status and patient informed status.

Table 2. Patient Satisfaction and Patient Informed status.

\begin{tabular}{lll}
\hline Projects & Satisfaction & Informed \\
\hline Control Group, $(\mathrm{n}=51)$ & $7.7+1.15$ & $7.6+1.07$ \\
Intervention Group,$(\mathrm{n}=48)$ & $8.9+0.74$ & $9.0+0.66$ \\
P Value & 0.013 & 0.003 \\
\hline
\end{tabular}

The anxiety research result and depression research result from the questionnaire, such as SDS and SAS. In Table 3, all participants have improvement between preoperative 1 day and postoperative 3 day, but the participants have different result from the different nursing services. The intervention group has better performance than that of control group in SAS and SDS $(53.5+10.44$ vs $41.5+8.82 \& 49.75+9.45$ vs 40.25+5.11).

Table 3. The score of anxiety and depression from SDS and SAS (Mean $\pm S D$ ).

\begin{tabular}{|c|c|c|c|c|}
\hline \multirow{2}{*}{ Projects } & \multicolumn{2}{|l|}{ SAS } & \multicolumn{2}{|l|}{ SDS } \\
\hline & PR1D & PO3D & PR1D & PO3D \\
\hline Control Group $(\mathrm{n}=51)$ & $65.375 \pm 5.77$ & $53.5 \pm 10.44$ & $61.5+8.28$ & $49.75+9.45$ \\
\hline Intervention Group $(\mathrm{n}=48)$ & $64.625+8.03$ & $41.5+8.82$ & $62.125+6.17$ & $40.25+5.11$ \\
\hline P Value & 0.85 & $0.03 \overline{9}$ & 0.88 & 0.038 \\
\hline
\end{tabular}

PR1D $=$ Preoperative 1 day

PO3D $=$ Postoperative 3 day 


\section{Discussion}

From Orsaria's report, breast cancer is a heterogeneous disorder that is categorized by gene expression into five major biologically distinct subtypes: luminal A, luminal B, overexpressing, basal, and normal-like epidemics growth factor receptor-2 (HER2) [15]. The breast cancer is highest death rate of woman diseases in the world, accounting for 522,000 fatalities in 2012. Thus, it is the most famous malignant diseases in the world. In addition, breast cancer is the most common cancer in Egypt's woman, it accounts for $38 \%$ of every Egyptian woman, that there is an average age of 49.6 per 100,000 people [16]. Confirming the subtypes of breast is a important condition of effectively treating breast cancer, because treatment decisions depend on these subtypes [17]. Breast cancer is divided into the hormone receptor-positive $(65 \% \sim 75 \%)$, HER2-positive $(15 \% \sim 20 \%)$, and triple-negative (15\%) subtypes.

Base on our research result, the individual care of case manager has good improvement in breast cancer patient's mental health. In particular, the intervention group participants who receive individual care of case manager have better performance in satisfaction research, anxiety research and depression research. In research of satisfaction and informed, intervention group has higher score in the result, its results are statistical significance. Additionally, the intervention group has greater change in the research result of anxiety and depression, the individual care of case manager has better influence to the breast cancer patient. In limitation, the sample size is limit other result to analyze, its result number is too few to difficult to make a persuasive results.

\section{References}

[1] Bray F, Ferlay J, Soerjomataram I, Siegel RL, Torre LA, Jemal A. Global cancer statistics 2018: GLOBOCAN estimates of incidence and mortality worldwide for 36 cancers in 185 countries, CA Cancer J. Clin. 2018; 68 (6): 394-424.

[2] Berry DA, Cronin KA, Plevritis SK, et al. Effect of screening and adjuvant therapy on mortality from breast cancer. N Engl J Med. 2015; 353: 1784-92.

[3] Siegel RL, Miller KD, Jemal A. Cancer statistics, 2018, CA Cancer J. Clin. 2018; 68 (1): 7-30.

[4] Liu S, Wicha MS. Targeting breast cancer stem cells, J. Clin. Oncol. 2016; 28 (25): 4006-4012.

[5] Cho N, Han W, Han BK, et al. Breast cancer screening with mammography plus ultrasonography or magnetic resonance imaging in women 50 years or younger at diagnosis and treated with breast conservation therapy. JAMA Oncol 2017; 3: 1495-502.

[6] Monticciolo DL, Newell MS, Moy L, Niell B, Monsees B, Sickles EA. Breast cancer screening in women at higher-than-average risk: recommendations from the ACR. J Am Coll Radiol 2018; 15: 408-14.

[7] Grunfeld E, Hodgson DC, Del Giudice ME, Moineddin R. Population-based longitudinal study of follow-up care for breast cancer survivors. J Oncol Pract. 2017; 6: 174-81.

[8] Isen JC, Ogarek JL, Goldenberg EJ, Sulo S. Impact of a chronic painprotocol on emergency department utilization. Acad Emerg Med. 2016; 23 (4): 424-432.

[9] Soril LJJ, Leggett LE, Lorenzetti DL, Noseworthy TW, Clement FM. Reducing frequent visits to the emergency department: a systematic re-view of interventions. PLOS ONE. 2015; 10 (4): e0123660.

[10] Seaberg D, Elseroad S, Dumas M, et al. Patient navigation for patientsfrequently visiting the emergency department: a randomized, controlledtrial. Acad Emerg Med. 2017; 24 (11): 1327-1333.

[11] Mercer T, Bae J, Kipnes J, et al. The highest utilizers of care: individual-ized care plans to coordinate care, improve healthcare service utilization, and reduce costs at an academic tertiary care center. J Hosp Med. 2015; 10 (7): 419-424.

[12] Grover CA, Sughair J, Stoopes S, et al. Case management reduces lengthof stay, charges, and testing in emergency department frequent users. WestJ Emerg Med. 2018; 19 (2): 238-244.

[13] White D, Leach C, Sims R, Atkinson M, Cottrell D. Validation of the Hospital Anxiety and Depression Scale for use with adolescents. Br J Psychiatry 1999; 175: 452-454.

[14] El-Rufaie O, Absood G. Validity study of the Hospital Anxiety and Depression Scale among a group of Saudi patients. Br J Psychiatry 1987; 151: 687-688.

[15] Orsaria P, Chiaravalloti A, Caredda E, Marchese PV, Titka B, Anemona L, Portarena I, Schillaci O, Petrella G, Palombi L, Buonomo OC. Evaluationof the usefulness of FDG-PET/CT for nodal staging of breast cancer. Anticancer Res. 2018; 38 (12): 6639-6652.

[16] Youssef AI, Hassan AA, Mohammed SA, Ahmed HA. Distribution of thechemokine receptor-5 gene in Egyptian breast cancer patients. Benha Medical J. 2018; 35 (1): 49.

[17] Sorlie, C. M. Perou, R. Tibshirani, T. Aas, S. Geisler, H. Johnsen, T. Hastie, M. B. Eisen, M. van de Rijn, S. S. Jeffrey, T. Thorsen, H. Quist, J. C. Matese PO. Brown D. Botstein, P. E. Lonning, A. L. Borresen-Dale, Gene expression patterns of breast carcinomas distinguish tumor subclasses with clinical im-plications, Proc. Natl. Acad. Sci. U. S. A. 2017; 98: $10869 \mathrm{e} 10874$. 